\title{
Discussion on connotation of traditional culture in contemporary literature
}

\author{
Yanhong Zhang \\ Jilin Radio and TV University Songyuan Branch, Songyuan, 138000, China
}

\begin{abstract}
Keywords: Contemporary literature; Traditional culture; Cultural connotation; Cultural inheritance
\end{abstract}

\begin{abstract}
Under the era background that economic society of China develops constantly, many people's spiritual civilization has been replaced with material civilization and a trend of weakening has been shown gradually. Especially, traditional culture stays at a passive and weak position increasingly. Some people even abandon it. In fact, profound connotation of traditional culture is still bred in contemporary literature of China. The reason for this is that connotation of traditional culture is of important value for contemporary literature undoubtedly and contemporary literature may extract excellent connotation of traditional culture to create its own content. Thus, when traditional culture is perfected continuously, development of contemporary literature is driven as well. Consequently, when source and basis of connotation of traditional culture are found, innovative development of contemporary literature is realized as well.
\end{abstract}

\section{Introduction}

Under the background that contemporary culture develops, traditional culture has been re-surveyed by a number of people and many people begin to think that traditional culture should be re-valued and re-excavated and a social subject of traditional culture with features should be formed. Consequently, peaks about traditional culture learning, for instance, great mass fervor about studies of Chinese ancient civilization and confucianist, appear in Chinese society again at present. In essence, this is an essential product which appears after a relatively orderly social mechanism has operated in modern China since traditional culture has never left our historical arena really since its birth. Then, it is obvious that contemporary literature, which is closely related to traditional culture, does not abandon traditional culture. The two have close relationship, i.e., they are related to and linked with each other. In another word, contemporary literature cannot be separated from profound connotation of traditional culture certainly. Innovation can be carried out for creation of contemporary literature by excavating excellent essence in traditional culture again, which will make literary creation show dual attributes, i.e., traditional and modern attributes. In this thesis, we will take Taoist culture, one of the most typical representatives of traditional culture, for example to implement analysis. In addition, we analyze minority culture and folk culture to make us understand profound connotation of traditional culture in contemporary literature, deal with the relationship between contemporary culture and traditional culture and walk out of spiritual dilemma.

\section{Dissociative spirit in traditional Taoist culture}

In traditional culture system of China, Taoist culture often appears via a dissociative mental state. This kind of cultural and spiritual connotation just adapts to the social atmosphere of China at the beginning of the $20^{\text {th }}$ century. Western democratic thoughts entered China successively at that moment, people showed different attitudes towards this. Some of them deemed that entrance of western cultural thoughts was good, but some others thought this affected and damaged traditional culture. Men of literature and writing tried to find basis of their own cultural creation in such a cultural environment. They could not add western cultural elements to literary creation randomly. Thus, there was just a point at which dissociative spiritual state of Taoist culture and original intention of scholars' creation were integrated. Men of literature and writing tried to realize personalization liberation in their literary creation and accorded with practical demands of era 
development via application of traditional culture to some extent at that time. Actually, this is means that traditional Taoist culture let literary creation of scholars had a deep cultural foundation and powerful emotional support in order that they won emotional resonance and wide acceptance in literary creation at that moment.

For instance, $\mathrm{Lu}$ Xun, a contemporary litterateur of China, is one of the representatives of this kind of dissociative mental stage of Taoist school. His A Madman's Diary shows the rebellion spirit that Taoist school stays in a dissociative state and he uses a number of Chuang-Tzu's linguistic literary quotations to apply and permeate inheritance of our traditional Taoist culture. He also tries to analyze social status of that era via literary creation and utilizes the said madman or maniac to form a huge contrast with social reality, which makes people clearly feel there is significant difference between figures described by $\mathrm{Lu} \mathrm{Xu}$ and normal ones. In addition, Guo Moruo and $\mathrm{Yu}$ Dafu permeate rebelling thoughts of Taoist school in their own literary works, which not only shows their literary creation feature that they recreate by themselves and even have autosadism and explains traditional culture of China well.

\section{Respect for nature in traditional Taoist culture}

In Taoist culture, Chuang-Tzu is a representative. He advocates naturalness largely. Nature is the most lofty aesthetics and philosophy in Taoist culture. It not only stands for nature of objective world but also represents naturally formed attitudes and thoughts. The main reason for this is that people begin to purpose nature regression in the aspect of spiritual civilization when material civilization of human society develops increasingly in order to obtain sense of constraint in the aspect of spiritual civilization. As a matter of fact, lots of contemporary litterateurs work hard to try naturalness regression of this kind of ideology and culture. In other words, they are dissatisfied with and depressed about development of material civilization to some extent and try to find the said cultural foundation via natural cultural regression again, attack humanity degeneration and disintegration strongly when material civilization develops rapidly and then find purity and naturalness of life.

Shen Congwen, a contemporary writer of China, is a representative. He attaches importance to naturalness, so readers usually see sentences and scenes with strong naturalness in his novels where naturalness is used to reflect internal features of novels. Besides, his novel creation surpasses naturalness to some extent indeed so that people see nature reaches people's lofty realm. In this novel creation, he is good at experiencing nature and can analyze beauty of life in nature and obtain a great many of materials for his literary creation. Thus, he usually separates figures in his novels. As a result, when people feel charm of nature where people stay beyond the noisy world, he also integrates figures with scenes and builds an environment and atmosphere of harmonious nature as well. In his literary works, people and nature are integrated and people are an important component of nature and act as a representative with the most spiritual height in nature. This sufficiently shows Confucianism has lost constraining force and everything is random. Additionally, Lin Yutang also advocates natural randomness, uses naturalness thought of Taoist to arm himself, realizes changes in literary thought, surpasses politics and gets psychological liberation.

\section{Freedom of personality in traditional Taoist culture}

In accordance with cultural tradition of Taoist school, pursuit for freedom is persistent. However, self-contained and slight cultural thoughts and attitudes towards life are also contained simultaneously. Essentially, this is consciousness of tragedy of Taoist school. Thus, free pessimism is scattered in traditional Taoist culture and full-bodied sadness and mawkishness are also presented, telling people everything in the world survives in painfulness, there is no need to pursue externally social things excessively and it will be the best to satisfy development of our free personalization as much as possible. In their opinions, final home of people is death and no one can avoid reality of sadness. This is survival law of nature. Thus, people do not need pursue too many external things but try their best to pursue self-contained and slight spiritual realm to find steadiness and freedom in 
inner heart by this. In the space where people's personality develops freely, they can comprehend tragedy color of life profoundly and realize self-atonement via lofty spiritual realm. As a result, people sublimate themselves from worldly real environment to higher spiritual level and obtain spiritual pleasure brought by self-recreation.

Liang Qiushi, a contemporary litterateur, is a representative of writers with free and easy personality. His literary work Yashe describes worldly environment in one paragraph and shows readers sense of elegant and refined humor overall. We may feel sense of freshness and nature deeply in sentences and words of his works, i.e., the writer breaks away from the objective world. He places himself beyond everything in the world and expresses the high-end interest that he will not bothered by things in the world. This refutes and fights against sociality and utilitarian nature of secular culture and pursues individuation and free features of literary creation.

\section{Minority culture in traditional culture}

Since China is a multinational country, traditional culture does not refer to Taoist culture only but contains abundant and diversified national cultures. Such minority cultures are unique cultural heritage and treasure of each nation and have special inheritance ways. We may find much traditional culture of minorities in contemporary literature works. It is an important component of our traditional culture, has unique cultural deposits and characteristics and acts as a significant branch of traditional culture. Thus, we must protect and inherit traditional culture of minorities via unique methods and try to reduce and avoid artificial interference or cultural infestation as much as possible. Although contemporary literature of China ignores minority culture to some extent, many literary creators pay more attention to inheriting and permeating traditional culture of the Han nationality until Alai a minority writer attracts people's attention to minority culture, especially, Tibetan culture, by virtue of his Things Have Come to A Close. The work contains features of full-bodied Tibetan culture and is a piece of excellent works, which uses a brand-new perspective and words to show people traditional Tibetan culture. It integrates Tibetan culture and improves cultural deposits of the work largely.

Actually, Tibetan literary itself develops gradually based on various news themes and lofty spiritual realm. Meanwhile, it is restrained and affected by traditional national culture of Tibetan people. Besides, Tibetan literary absorbs different cultures innovatively and enriches its literary content and writing skills constantly, which promotes healthy and rapid development of Tibetan literary effectively. Thus, Tibetan literatures not only have distinct national characteristics and full-bodied regional features but also show unique lasting appeal of national culture and become a characteristic branch of art in the contemporary literary world of China. Specially, Tibetan literatures consult, re-show and transform traditional folk literary themes and Buddhism themes. All of these themes vary with historical changes and have significant impacts on cotemporary writers' literary creation. A number of Tibet writers carry out literary creation by consulting famous figures in stories. The only difference is that the ways in which they consult such figures are different. In detail, some writers narrate their literary concepts by borrowing frames of stories, while some writers borrow covers of stories to spread spiritual connotation of stories again and some scholars implement literary creation based on critical inheritance and endow their stories with new connotation. All of these reflect contemporary literatures inherit and develop traditional culture of Tibetan people and act as a healthy and reasonable borrowing method. For instance, Tibet, Soul Tied to A Leather Button written by Tashi Dawa, a contemporary Tibetan writer, is a novel that is created by borrowing tales and legends. It is based on tales and legends and views Tibetan culture from a contemporary perspective rationally. This is integration between modern civilization and traditional culture. The author deals complicated relations between the two well. At the same time, some contemporary Tibetan writers permeate traditional Tibetan songs in a literary form into contemporary Tibetan literary creation, which is a unique novel literary structure and has cultural toughness and durability to a larger extent. Additionally, some contemporary Tibetan writers re-show national cultural psychology artistically via unique traditional Tibetan culture and guide readers to have more profound values and deeper comprehension about spiritual orientation. 


\section{Folk culture in traditional culture}

In addition to the foregoing Taoist culture and minority culture, traditional culture of China contains various folk cultures. All of them are indispensable and important cultural foundation in historical development of Chinese nation and will not vary with changes of the times but have spiritual core that our nation owns and are featured by stability to some extent. The folk culture mentioned here mainly refers to a cultural type which is relative to official culture. The said is a type of mainstream and characteristic cultures formed under administrative control of the country gradually. Folk culture has different featured compared with official culture. Specifically, folk cultures are a type of cultures scattered in different regions and featured by dispersion. It is difficult to control them since they are basically scattered in different kinds of regional environment and characterized by local color largely. Meanwhile, folk cultures will improve itself as people's living habits change and are featured by degree of freedom to some extent, which also decides folk cultures have much permeability in traditional culture. Additionally, folk cultures are characterized by personality. Usually, different explanation and opinions appear because of various ideas, which makes folk cultures are featured by complexity and refutation so that it is almost impossible to realize real consistency and uniformity. Even so, folk cultures are still an important component in system of our traditional culture, play an irreplaceable role in people's mind and exert important effect, enjoy popular support and are related to people's daily life closely. It is more easily to inherit and develop them in traditional culture. Besides, they can approach people's livelihood to a larger extent and win literary creators' favor. Therefore, we can easily find folk cultures in contemporary literatures. For instance, Jin Yong, a famous Kung fu novelist, boldly introduces many folk cultures to his works and realizes effective inheritance and energetic promotion of our folk cultures.

\section{Reference:}

[1] Xu Meiheng. Unique artistic achievement of Tibetan writers' full-length novels [J]. Tibetan Studies, 2006(01).

[2] Yang Jianjun. Belief in China -introspection on Zhang Chengzhi's novel writing with the Huis themes [J]. Journal of China Three Gorges University (Humanistic and Social Science Edition), 2010(05).

[3] Zeng Shaoyi. Is it history of 'contemporary literature' of China or literary history of contemporary China - Thinking on history of China's 'contemporary literature' [J]. Journal of Radio and TV University (Philosophy and Social Science Edition), 2005(01).

[4] Zhu Defa. Mutual intelligibility of ancient and contemporary literature [J]. Journal of Xinxiang Teachers College, 2005(03). 